\title{
Obvious More Things To Do
}

Matt Hetherington

\author{
MOW CARPET \\ UNPACK HEAD \\ RETURN NEIGHBOURS FOR EXCHANGE \\ REINFORCE FENCES \\ WATER DIRT \\ REPOT BELLY \\ CHECK OIL \& WATER \\ SERVICE WIFE \\ MILK BABY'S BOTTLE \\ REMEMBER BILLS \\ FORGET DREAMS \\ 15 MINS MEDITATION \\ BEER, WINE, CHEESE, KITTY LITTER \\ RECYCLE WHINING CHILD \\ WASH TV \\ DESEX DOG \\ CONDOMS, ASPIRIN, VITAMINS \\ FERITILISE SKY
}

